\title{
Increased Wear Resistance of High-Speed Tools Due to Diffusion Discrete Oxidation
}

\author{
Elena A. Chekalova ${ }^{1, ~}{ }^{*}$ and Andrey $V$. Zhuravlev ${ }^{1, \mathrm{~b}}$ \\ ${ }^{1}$ Moscow Polytechnic University, Moscow, Russia
}

\begin{abstract}
Comparative studies of the effect of discrete surface hardening by standard ion-plasma technology and discrete oxidation technology on wear resistance have been carried out. Metallographic studies have shown that discrete oxidation has a polycrystalline structure. It was found that the technology of discrete oxidation makes it possible to increase the hardness by $31 \%$ in relation to the uncoated material, and the wear resistance of the cutting tool with oxidation is 1.5-3 times higher than that of the tool hardened by the standard ion-plasma technology.
\end{abstract}

\section{Introduction}

There is a variety of materials to be processed, and when choosing a processing tool, it is necessary to take into account the specifics of processing a particular material, as well as environmental and economic factors. In the process of cutting, the tool interacts with the material of the workpiece, which is accompanied by a complex set of physicochemical phenomena, namely, the surface layer undergoes elastoplastic deformation $[1,2,3,4,5]$.

Currently, extensive work is underway to analyze various types of coatings with different structures. The number of coating components changes, additional elements vary, the number of coating layers changes. $[4,5,6,7,8]$.

The use of tools with wear-resistant coatings allows you to solve a number of problems of technological cutting operations associated with increasing productivity, accuracy and quality of processing, reducing the consumption of expensive materials.

However, when machining, a multi-coated cutting tool is often destroyed. The fracture process is usually accompanied by the formation of cracks in the weaker layer. Then the crack reaches the interface between two layers of the multilayer coating and transforms into a slip crack, which develops along this boundary, delaminating the multilayer coating. At this time, a microcrack appears, which over time will lead to the destruction of this layer. The elastic modulus and fracture toughness of the coating material have a great influence on the mechanical properties of coatings. To increase the wear resistance of the coated tool, alloying elements are used as soft interlayers: Zr, Mo, Al, etc., which affect the structure and physical and mechanical properties of the coatings. Such an ambiguous change is associated with a different effect of chemical elements on the reduction of stresses acting in the instrumental basis $[9,10,11,12,13]$.

\footnotetext{
* Corresponding author: alenka.2019@inbox.ru
} 
To increase the efficiency of cutting tools with an ion-plasma coating and reduce the rate of premature wear, the appearance of cracks, the effect of coating unevenness can be used, i.e. application of ion-plasma coating by mesh method, (Fig. 1).

The ion-plasma mesh coating is present along the entire surface of the sample, both in the cells and at their boundaries, while the thickness in the cells is $1.5-2 \mu \mathrm{m}$, and at the border of the cells is $0.1 \mu \mathrm{m}$. However, this coating has a number of disadvantages: first, the presence of droplet phases and the formation of delamination in the coating is noted on the sample surface. Secondly, the coating technology is difficult due to the loose adhesion of the stainless mesh to the sample. Thirdly, this method is only for a single flat cutting tool, and is not suitable for a complex profile one.

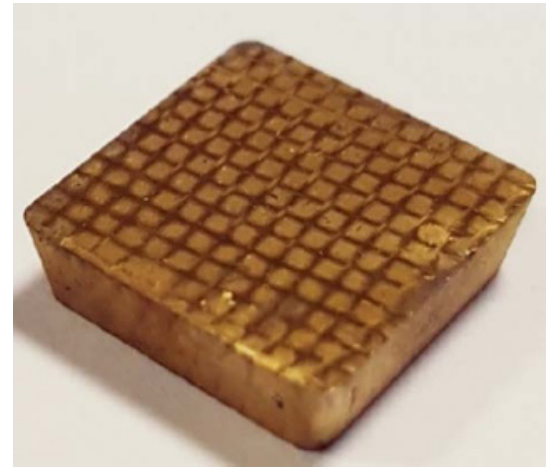

Fig. 1. Appearance of the surface of a high-speed plate with an ion-plasma mesh TiN coating.

It can be assumed that the unevenness of the coating will increase the tool resistance to deformation changes due to the independence of deformation damage of individual cells. Thus, to increase the durability of the cutting tool, it is necessary that the interlayer surface be a barrier against fatigue cracks.

For the cutting tool, another method is assumed, which forms the surface structure with fragments of the coating and with the presence of areas without coating $[13,14,15]$.

The formation of a discrete oxide layer on the surface contributes to stress relaxation, which leads to the prevention of crack propagation and even its stoppage during operation. This oxide layer increases rigidity while maintaining strength.

The aim of this work is to study the physical, mechanical and wear-resistant properties of a discrete oxide layer on a high-speed tool.

\section{Research Methodology}

When applying diffusion discrete oxidation, physical and chemical processes occur. During the corona treatment of the surface, the electrons cause the destruction of long chains, leading to an increase in free bonds. Loose bonds form carbonyl groups with high surface energy due to the interaction of ozone atoms created by an electric discharge. Thanks to the developed resonant circuit with a feedback system, important material properties are preserved. Oxygen, penetrating into the crystal lattice of the metal, forms solid solutions, and thereby increases the hardness and strength of a thin oxide film on the surface of the tool material, but at the same time, without changing the structure of the substrate, and as the temperature rises, the oxides pass into a more stable state $[16,17,18,19,20]$. High-speed steel P6M5 was used as the research material. 


\section{Discussion of the results of the study}

During the formation of discrete oxidation, physical and chemical processes occur. The distribution of elements over the depth of the coating material was obtained by X-ray spectral analysis.

It was found that the coating contains $\mathrm{Fe}, \mathrm{Cr}, \mathrm{W}, \mathrm{V}, \mathrm{Mo}, \mathrm{Co}, \mathrm{O}, \mathrm{C}$ (Fig. 2, 3). At a depth of $500 \mathrm{~nm}$, the Fe content is $76 \%$, while at a depth of $4000 \mathrm{~nm}$ it is $84 \%$. The content of $\mathrm{Cr}$, $\mathrm{W}, \mathrm{V}, \mathrm{Mo}$, Co practically did not change, at the same time, it was found that oxygen is present only in the surface layer of the coating and the oxygen content is approximately $0.08 \mathrm{wt}$. shares (table 1). Thus, it can be argued that the decrease in the Fe content in the surface layer is due to the occurrence of the oxidation process and the formation of $\mathrm{Fe}_{\mathrm{x}} \mathrm{O}_{\mathrm{y}}$ oxides. Micro $\mathrm{X}$-ray spectral analysis (Fig. 3) confirmed a significant decrease in the Fe content in the coating. Chemical composition of the surface oxide layer on steel P6M5 after treatment, \%: Fe-67; Cr-4.1; W 8.2; V 2.7; Mo-6.0; O-10.4. Micro X-ray spectral analysis, carried out on a scanning electron microscope, showed that the oxide layer obtained by the diffusion method has a polycrystalline structure (Fig. 4), with a grain size of about $4 \mu \mathrm{m}$.

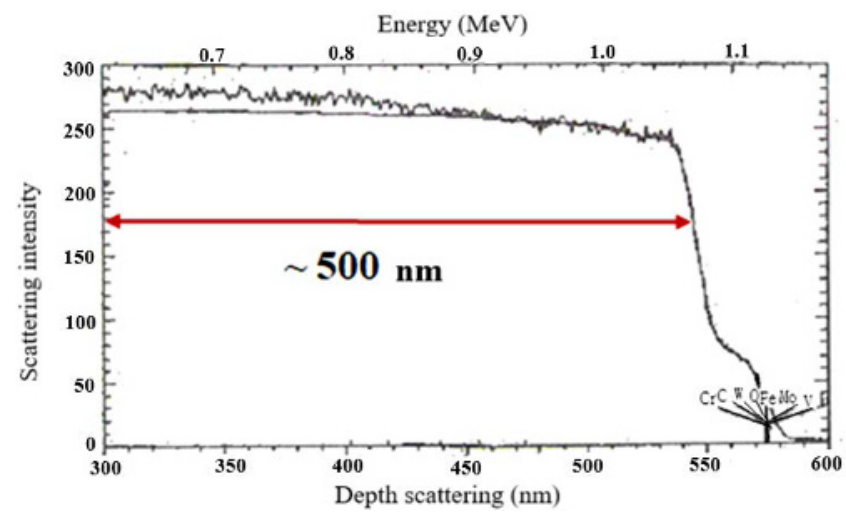

Fig. 2. Evaluation of the thickness of the oxide layer on high-speed steel P6M5 using the scattering spectrum of hydrogen ions $\mathrm{H}^{+}$

Table 1. Chemical composition of high-speed steel P6M5 with discrete diffusion oxidation

\begin{tabular}{|c|c|c|c|c|c|c|}
\hline \multirow{2}{*}{$\begin{array}{l}\text { Depth of bombardment } \\
\text { with hydrogen ions, nm }\end{array}$} & \multicolumn{7}{|c|}{ Elements, mass. Share. } \\
\cline { 2 - 7 } & Fe & Cr & W & V & Mo & O \\
\hline 500 & 0.67 & 0.041 & 0.082 & 0.037 & 0.06 & 0.104 \\
\hline 4000 & 0.84 & 0.041 & 0.082 & 0.037 & 0.06 & 0.00 \\
\hline
\end{tabular}

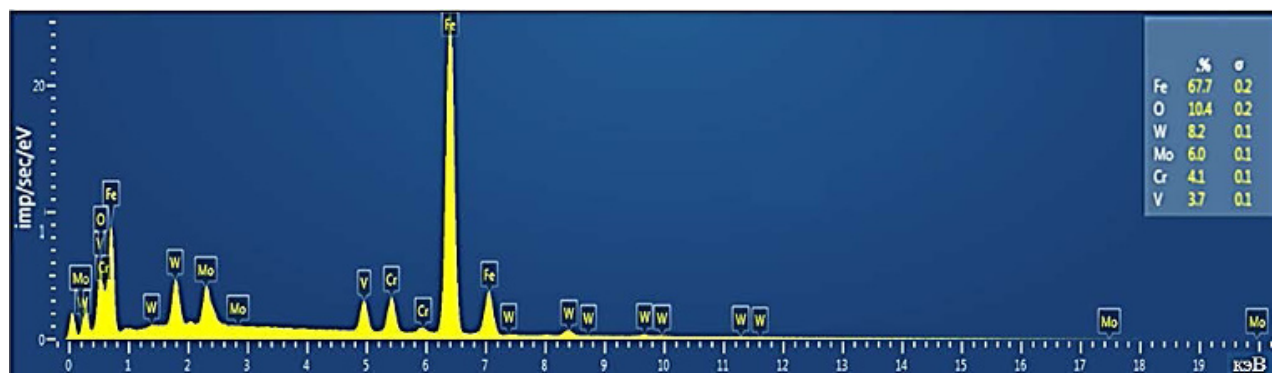

Fig. 3. Spectrogram of the oxidized layer on a sample of high-speed steel P6M5 


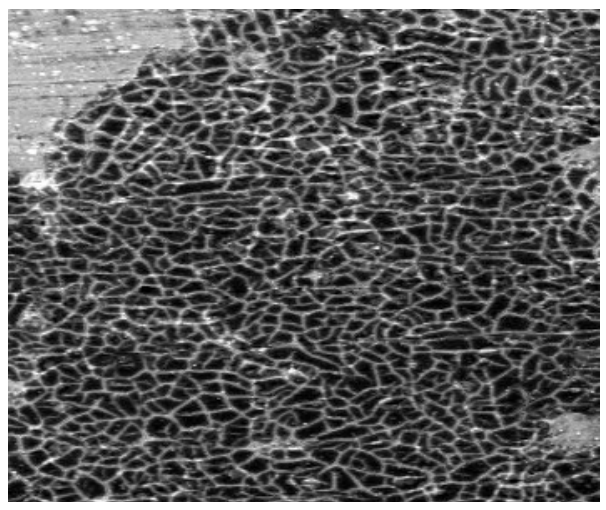

Fig. 4. The microstructure of the surface of the oxide sample from high-speed steel P6M5 (x500)

In the course of metallophysical and metallographic studies, the thickness of the coating was obtained, which is $\sim 500 \mathrm{~nm}$ (Fig. 2), while the hardness of the discrete oxide layer exceeded the hardness of the base metal by $31 \%$, Fig. 5

The results of determining the hardness of the base metal (steel P6M5) with oxidation showed that the hardness values corresponded to $\mathrm{H}_{\mathrm{IT}}=16304 \mathrm{H} / \mathrm{mm}^{2}$.

For the base metal (steel P6M5) without a discrete oxide layer, the average value of $\mathrm{H}_{\mathrm{IT}}$ $=12322 \mathrm{H} / \mathrm{mm}^{2}$. This increase in hardness is due to the iron oxide content in the coating.

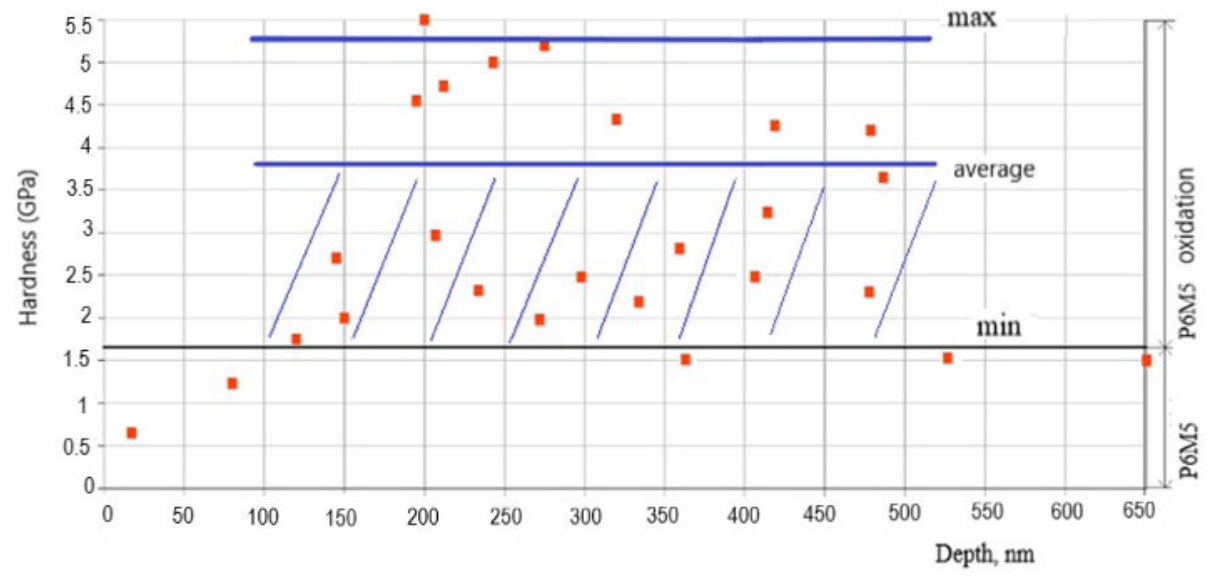

Fig. 5. Distribution of hardness along the depth of the surface layer of the sample from high-speed steel P6M5 at a maximum load of $12000 \mathrm{mkH}$

Research has been carried out on the cutting properties of tools made of high-speed steel, with a discrete oxide layer, with a continuous coating and without a coating.

To establish the features of the process of cutting and wear of a tool made of high-speed steel with a discrete oxide layer in comparison with the corresponding parameters of the control tool, extensive studies of the turning process were carried out. Investigations of the kinetics and mechanisms of wear were carried out during longitudinal turning of $40 \mathrm{X}$ structural steel (Fig. 6). 


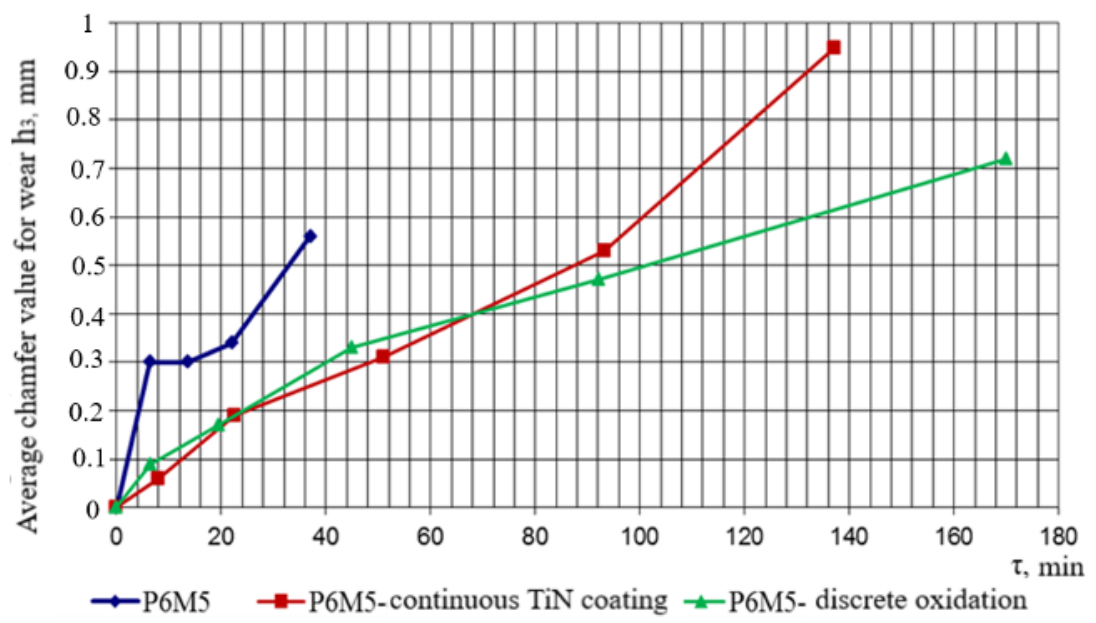

Fig. 6. Generalized curves $\bar{h}_{3}=\mathrm{f}(\tau)$, obtained during longitudinal turning of steel 40X (HB220) c v $=$ $65 \mathrm{~m} / \mathrm{min} ; \mathrm{s}=0.175 \mathrm{~mm} / \mathrm{ob}$; $\mathrm{t}=1.0 \mathrm{~mm}$ with a tool made of high-speed steel P6M5

It has been established that the wear rate of a high-speed tool with a discrete oxide layer relative to a continuous coating at the running-in stage decreases, and the value of the wear chamfer decreases $\bar{h}_{3}$,.when exceeded, the stage of steady-state wear begins.

In addition, during the running-in wear stage, the discrete oxide layer reduces the thermomechanical stresses on the tool pads, which extremely effectively inhibits flank wear.

\section{Conclusions}

1. Thus, a cutting tool with a discrete oxide layer can significantly increase the durability, reducing the tendency to loss of form stability and elastic deflections when thermomechanical stresses arising during cutting are applied.

2. It was established that the composition of the discrete oxide layer includes oxides $\mathrm{FeO}$, $\mathrm{Fe}_{3} \mathrm{O}_{4}$ and $\mathrm{Fe}_{2} \mathrm{O}_{3}$ in the form of a thin discrete film. In this case, the structure of the base metal does not undergo noticeable changes in the surface layer.

3. The structure of the discrete oxide layer can serve as an integral characteristic capable of preventing crack propagation and even stopping it during operation.

4. It has been established that the discrete oxide layer makes it possible to increase the wear resistance of the high-speed tool P6M5 when turning steel 40X by 4-5 times as compared to the control tool and by 1.5-3 times as compared to the tool with a continuous coating.

\section{References}

1. Lakhtin, Yu.M. Chemical-thermal processing of metals: a textbook for universities / Yu. M. Lakhtin, B.N. Arzamasov. - M.: Higher School, 1985. - 256 p.

2. V.P. Tabakov Formation of wear-resistant ion-plasma coatings of the cutting tool. Mechanical Engineering, Moscow, (2008) (in Russian)

3. Vereshchak, A.S. The performance of the cutting tool with wear-resistant coatings / A.S. Vereshchak. - M.: Mechanical Engineering, 1993.- 330 p. 
4. Arzamasov, B.N. Ion chemical-thermal treatment of alloys / B.N. Arzamasov, A.G. Bratukhin, Yu.S. Eliseev, T.A. Panagioti. - M.: Publishing House of MSTU. N.E. Bauman, 1999 - 400 p.

5. Petrova, L.G. On the possibility of obtaining nanostructured coatings on steel products by surface modification / L.G. Petrova, I.S. Belashova, V.A. Alexandrov, P.E. Demin, A.A. Brezhnev // "Bulletin of the Moscow Aviation Institute" v.21. No. 2, 2014, p. 75 82.

6. Chudina, O.V. Surface alloying of carbon tool steels using laser heating / O.V. Chudina, A.A. Brezhnev // "Technology of metals" No. 2, 2014, p.19-24.

7. Belashova, I.S. Change in the mechanical and thermal characteristics of tool steels during laser alloying / I.S. Belashova, D.P. Shashkov // "Strengthening Technologies and Coatings" No. 4, 2007, p. 39-43.

8. Kuzmenko, Yu.N. Improving the quality of cutting tools from high-speed steel / Yu.N. Kuzmenko, V.M. Ryabikina et al. // Bulletin. TSNIICHM. Chermetinformatsya. - 1987. - No. 17. - S. 12 - 24.

9. Bertenev S.S. Knock coatings in mechanical engineering / S. S. Bertenev, Yu. P. Fedko, A. I. Grigorov. - L.: Engineering, 1988.- 215 p.

10. Filimonov, V.I. Yakovlev, M.A. Korchagin et al. The processes of structure formation and detonation-gas deposition of protective coatings from composite powders $\mathrm{TiA}_{3}$ and No. 3A1 // Combustion and Explosion Physics, 2008, V. 44, No. 5, P. 106-111.

11. Kulikov I.S. Metal deoxidation / I.S. Kulikov. - M.: Publishing house "Metallurgy", 1975. - $504 \mathrm{p}$.

12. Vereshchak A.S. Improving the working capacity of the cutting tool in the processing of difficult-to-machine materials through the complex application of a nanostructured wear-resistant coating and a hard alloy of optimal composition. Vereshchak, A.V. Dacheva, A.I. Anikeev // Bulletin of the Moscow State Technical University MAMI. 2010. No. 1 (9). S. 99-106.

13. Yu.V. Lakhotkin, V.P. Kuzmin, V.V. Dushik, T.V. Rybkina. A new low-temperature method for applying solid nanostructured coatings to complex products // Strengthening Technologies and Coatings, 2013, No. 6, P. 9-15.

14. Vidakis N. The VDI-3198 indentation test evaluation of a reliable qualitative control for layered compounds. Vidakis N., A. Antoniadis, N. Bilalis // Technological Educational Institute of Crete, Technical University of Crete. Greece. 1992. P. 6.

15. Chekalova E. A. The method of forming a wear-resistant coating on the surface of a metal part / E. A. Chekalova, P. D. Chekalov, R. D. Solomatina // Patent 2548835 of the Russian Federation for the invention, IPC C23C8 / 36. Published on April 20, 2015 Patent holder: Chekalova E.A.

16. Chekalova E.A. Study of wear-resistant coatings on VT3-1 / E titanium alloy. A. Chekalova // "Material Science" - 2017. - No. 9. - P. 3 - 6.

17. E.A. Chekalova Increase in productivity of complex-profile tools made of high-speed steels due to discrete diffusion hardening / E.A. Chekalova, A.V. Zhuravlev // Mechanical Engineering and Engineering Education - 2019. №4 (61). - S. 28 - 31

18. Chekalova E.A. The study of diffusion local coating of the oxide type on the tool material / E. A. Chekalova // "Material Science" - 2017. - No. 8. - P. 24 - 29.

19. E.A. Chekalova Discrete oxidation of a complex-profile tool made of high-speed steels. Chekalova, A.V. Zhuravlev // "Strengthening technologies and coatings" - 2019 Volume 15. - №12 (180). - P. 546 - 549. RSCI (on the Web of Science platform ISSN: 1813-1336)

20. Chekalova E.A. Investigation of the structure of a discrete oxide coating on a highspeed and carbide tool / E. A. Chekalova // "Hardening technologies and coatings" 2017. - No. 7. - S. 309 - 313. 